\title{
Analysis on Influencing Factors of Anti Hypertensive Effect of Scraping on Essential Hypertension
}

\author{
Liu Hai-hua ${ }^{1}$, Yang Jin-sheng ${ }^{2}$, Liu Zhao², Wu Yuan² and Wang Ying-ying ${ }^{2}$ \\ ${ }^{1}$ Beijing Geriatric Hospital, China \\ ${ }^{2}$ Institute of Acupuncture and Moxibustion of China Academy of Chinese Medical Sciences, China
}

Submission: February 05, 2018; Published: March 28, 2018

*Corresponding author: Liu Hai-hua, Beijing Geriatric Hospital, China, Email: 827448010@qq.com

\begin{abstract}
Objective: To explore the influencing factors of anti-hypertensive effect of scraping on essential hypertension, and to determine the crowd appropriate for anti-hypertension by scraping.

Method: Eighty-nine patients with essential hypertension (conforming to the inclusion criteria) were included into this study, and were treated by scraping. The main scraping location included governor vessel and bladder meridian on the neck and back, from Qūchí (LI 11) to Shŏusānlǐ (LI 10), and from Zúsānlĩ (ST 36) to Fēnglóng (ST 40). Scraping was conducted for 10 times on each site with the width of about $5 \mathrm{~cm}$ and duration of $15 \mathrm{~min} /$ time. Blood pressure was monitored before scraping, immediately after scraping $(0 \mathrm{~h}), 0.5 \mathrm{~h}, 1 \mathrm{~h}, 1.5 \mathrm{~h}, 2 \mathrm{~h}, 3 \mathrm{~h}, 4 \mathrm{~h}$ and $6 \mathrm{~h}$ after scraping, and efficacy was analyzed statistically.
\end{abstract}

Result:

A. Systolic pressure and diastolic pressure at each period of time after scraping were lower than that before scraping, and the differences were statistically significant (all $\mathrm{P}<0.01$ );

B. It was indicated according to nonlinear regression analysis and factor analysis that the anti-hypertensive effect of scraping was positively associated with taking anti-hypertensive drugs and not having a history of smoking and drinking, and was negatively associated with age; based on the comparison among different patterns, the anti-hypertensive effect of scraping in patients with the type of exuberance of liver fire was the best, better in patients with the type of yin deficiency with yang hyperactivity, slightly poor in patients with the type of phlegm-damp congestion and exuberance, and worst in patients with the type of deficiency of both yin and yang.

Conclusion: Scraping can significantly and immediately lower blood pressure of patients with essential hypertension, and it has the best anti-hypertensive effect in young and middle-aged patients who are taking anti-hypertensive drugs, without such unhealthy living habits as smoking or drinking and with stable state of illness, and in crowd with the type of exuberance of liver fire and yin deficiency with yang hyperactivity.

Keywords : Scraping; Essential hypertension; Anti-hypertension; Influencing factors; Crowd

\section{Introduction}

Essential hypertension (EH), a syndrome with the main clinical manifestation of elevation of blood pressure, is one of chronic diseases with multi-factors commonly seen clinically, and is the important cause and risk factor of cardiovascular and cerebrovascular diseases. It has been confirmed from domestic and overseas researches [1] that prevention and control of blood pressure within normal range is an important way to reduce the incidence of cardiovascular and cerebrovascular diseases which are closely related to hypertension. At present, oral administration of anti-hypertensive drugs is still the main therapeutic method of EH clinically, however, more and more patients have requirements on seeking auxiliary treatment of hypertension with such physical therapies as acupuncturemoxibustion and scraping [2]. It was found from clinical practices that not all the patients are sensitive to acupuncturemoxibustion and scraping. In order to explore the influencing factors of anti-hypertensive effect of scraping on essential hypertension, and to determine the crowd appropriate for antihypertension by scraping, the immediately anti-hypertensive effects of scraping in 89 patients with essential hypertension before and after treatment were analyzed by the author, and the details were summarized as follows.

\section{Clinical Data}

\section{General information}

Eighty-nine patients with essential hypertension were selected from Acupuncture-moxibustion Hospital of China Academy of Chinese Medical Sciences, and the patients visited 
the hospital from July, 2013 to March, 2014. Among the 89 patients, male patients were 38 cases, and females were 51 cases. The age was from 25 to 78 years old with the average of ( $57 \pm 11$ ) years old; the shortest course of disease was 19 days, and the longest was 46 years with the average of $(8.49 \pm 8.79)$ years; 56 cases suffered from grade I hypertension, and 33 cases suffered from grade II hypertension; pattern differentiation: 27 cases with the type of exuberance of liver fire, 27 with the type of yin deficiency with yang hyperactivity, 20 with the type of phlegm-damp congestion and exuberance, and 15 with the type of deficiency of both yin and yang (Table 1).

Table 1: General information.

\begin{tabular}{|c|c|c|c|}
\hline & Male & Case & Proportion \\
\hline Sex & Female & 38 & $42.70 \%$ \\
\hline $\begin{array}{c}\text { Hypertension } \\
\text { grading }\end{array}$ & Grade I & 56 & $57.30 \%$ \\
\hline Family history & Yes & 33 & $37.10 \%$ \\
\hline $\begin{array}{c}\text { Pattern } \\
\text { differentiation }\end{array}$ & $\begin{array}{c}\text { None } \\
\text { Exuberance of liver fire }\end{array}$ & 27 & $36.90 \%$ \\
\hline $\begin{array}{c}\text { Yin deficiency and yang } \\
\text { hyperactivity }\end{array}$ & 27 & $30.30 \%$ \\
\hline $\begin{array}{c}\text { Phlegm-damp } \\
\text { congestion and } \\
\text { exuberance }\end{array}$ & 20 & $22.50 \%$ \\
\hline $\begin{array}{c}\text { Taking anti- } \\
\text { hypertensive } \\
\text { drugs }\end{array}$ & Yin and yang deficiency & 15 & $16.90 \%$ \\
\hline & Yes & 55 & $61.80 \%$ \\
\hline
\end{tabular}

\section{Diagnostic criteria}

Diagnostic criteria in Western medicine: by reference to the diagnostic criteria of hypertension in 2010 Chinese Guideline for Prevention and Treatment of Hypertension [1]. On the premise that without taking anti-hypertensive drugs, systolic pressure $\geq 140 \mathrm{mmHg}(1 \mathrm{mmHg}=0.133 \mathrm{kPa})$ and/ or diastolic pressure $\geq 90 \mathrm{mmHg}$ based on blood pressure measurement for 3 times on different days. Systolic pressure $\geq 140 \mathrm{mmHg}$ and diastolic pressure $<90 \mathrm{mmHg}$ was considered as isolated systolic hypertension, which can be diagnosed after excluding secondary hypertension.

Diagnostic criteria in traditional Chinese medicine: by reference to the diagnostic criteria of hypertension in traditional Chinese medicine in Guidelines of Clinical Research on Chinese New Herbal Medicine [3]:

A. Exuberance of liver fire: dizziness, headache, impatience and irascibility;

B. yin deficiency with yang hyperactivity: dizziness, headache, soreness of waist, knee weakness and vexing heat in the five centers;
C. Phlegm-damp congestion and exuberance: dizziness, headache, head with binding sensation, chest oppression and vomiting of phlegm-drool;

D. Deficiency of both yin and yang: dizziness, headache, soreness of waist, knee weakness, fear of cold and cold limbs.

\section{Inclusion criteria}

A. Patients with grade I and grade II hypertension conforming to the diagnostic criteria of essential hypertension in Western medicine;

B. With the age of 18-79 years old;

C. Without taking anti-hypertensive drugs;

D. Taking anti-hypertensive drugs, but with stable state of illness for over 2 weeks. Patients conforming to item (1)(2)(3) or (1)(2) (4) were included.

\section{Exclusion criteria}

A. Patients with secondary hypertension.

B. With severe primary diseases in heart, brain, liver, kidney or hematopoietic system, mental disorder and tumor.

C. Pregnant and lactating women.

D. With severe skin injury or skin disease on scraping site.

E. Allergic to scraping.

F. Overweight patients with body mass index (BMI) of $>30$. Patients conforming to any item in (1)(2)(3)(4)(5) were excluded.

\section{Methods}

Scraping therapy was given to the patients taking antihypertensive drugs on the basis of basic treatment, and patients without taking anti-hypertensive drugs were treated with scraping therapy directly.

\section{Scraping apparatus}

Scraping oil, scraping plate (provided by Beijing Jinlong Kangerfu Health Center, production license: XK16-1082634).

\section{Manipulation}

A. Preparation before scraping: the patient was asked in prone position with full exposure of neck and back; wet wipes were used to wipe the skin, and then scrapping oil was applied on the scraping site.

B. Scraping angle: $45^{\circ}$ between scraping plate and skin.

C. Scraping site: firstly, Fēngfŭ (GV 16) to Dàzhuī (GV 14) on governor vessel on the neck, areas along Jiājí (EX-B2) on both sides of neck, and Fēngchí (GB 20) to acromion on the lateral neck were scrapped; secondly, areas along governor vessel and bilateral foot tai yang bladder meridian on the back were scrapped; after then, the patient was asked in supine position, and Rényíng (ST 9) on the neck, Qūchí (LI 11) to Shŏusānlǐ (LI 10) of hand yangming large intestine meridian of upper limbs, Zúsānlǐ (ST 36) to Fēnglóng (ST 40) 
of foot yangming stomach meridian of lateral lower limbs, and Tàichōng (LR 3) area were scrapped; finally, the patient was asked in sitting position, and bilateral Tàiyáng (EX-HN5) to GB 20 on the head, and Băihuì (GV 20) to Yìntáng (EXHN3), GB 20 and GV 16 on the middle of head were scrapped.

D. Scraping manipulation: all patients were treated with moderate stimulation intensity, and the scraping intensity should be endurable; on the neck and back, subcutaneous capillaries should rupture, and subcutaneous static blood should be seen; on limbs and head, subcutaneous capillaries hyperemia and skin hot flashes should be seen.

E. Scraping time and frequency: scraping for 10 times was conducted on each site with the width of about $5 \mathrm{~cm}$; scraping lasted for $15 \mathrm{~min}$, and once therapy was needed.

\section{Notes}

Wind was avoided when scraping, keeping warm. If the room temperature was low, exposed location should be reduced; bath was avoided within $30 \mathrm{~min}$ after scraping, and cold and greasy food was forbidden; pregnant women and women in menstrual period were forbidden to have scraping on waist and abdomen. Scraping was also forbidden in people with such skin diseases as ulcer, severe allergy, nevolipoma, unexplained subcutaneous mass and new wound, such dysfunctions of blood coagulation as leukemia and thrombocytopenia; scraping was avoided in patients who were fasting, or patients with excessive tiredness, hypoglycemia, excessive weakness and nervous tension. Scraping manipulation should penetrate skin softly with endurable intensity; the intensity should be gentle for patients with hypotension or who were afraid of pain for avoiding faint.

\section{Efficacy Observation}

\section{Observational index}

Blood pressure: blood pressure of the right arm was measured by a calibrated Omron 7200 sphygmomanometer (license No.: L.S.Y.J.X. (quasi) 2009 No.2200129) in sitting position, including systolic pressure and diastolic pressure.

\section{Time points for blood pressure monitoring}

The patient was asked to arrive at the consulting room at 1:30 p.m., and blood pressure before scraping was measured after rest for $10 \mathrm{~min}$. Scraping lasted for $15 \mathrm{~min}$, and blood pressure immediately after scraping (2:00 p.m.), 0.5h, $1 \mathrm{~h}, 1.5 \mathrm{~h}, 2 \mathrm{~h}, 3 \mathrm{~h}, 4 \mathrm{~h}$ and $6 \mathrm{~h}$ after scraping were measured, respectively.

\section{Quality control}

As a continuous variable, blood pressure is affected by such factors as time, environment and emotion; therefore, blood pressure should be measured at 2:00-8:00 pm. under the same conditions like location, temperature, humidity, activity and etc. Blood pressure was measured at three different time points, and the mean value was recorded. The patient was asked to avoid exercising vigorously, lying down to sleep for a long time, smoking or drinking during measuring period.

\section{Statistical analysis}

SPSS19.0 software package was used to analyze data. Measurement data were expressed as mean \pm standard deviation $( \pm S$ ), and t-test was conducted for comparison before and after treatment; test statistics and the corresponding P-value were calculated, and the difference was statistically significant $(\mathrm{P}<0.05)$. Firstly, non-liner regression equation was adopted to find out the factors impacting anti-hypertensive effect of scraping, and then, factor analysis was applied to conduct stratified analysis on each influencing factor.

Results

\section{Comparison of blood pressure of patients with essential hypertension before and after scraping (Table 2)}

Note: Compared with before scraping on the same day, ${ }^{1} \mathrm{P}<0.01,{ }^{2} \mathrm{P}<0.05$.

Table 2: Comparison of blood pressure of patients with essential hypertension before and after scraping.

\begin{tabular}{|c|c|c|c|}
\hline \multicolumn{2}{|c|}{ Time } & $\begin{array}{c}\text { Systolic } \\
\text { Pressure }\end{array}$ & $\begin{array}{c}\text { Diastolic } \\
\text { Pressure }\end{array}$ \\
\hline Before scraping & $1: 45$ PM & $149.00 \pm 10.19$ & $85.30 \pm 10.96$ \\
\hline & $2: 00$ PM(0h) & $144.67 \pm 12.141$ & $83.48 \pm 11.131$ \\
\hline & $2: 30$ PM(0.5h) & $137.51 \pm 10.241$ & $81.06 \pm 10.561$ \\
\hline & $3: 00$ PM(1h) & $135.09 \pm 10.211$ & $81.24 \pm 9.951$ \\
\hline After scraping & $3: 30$ PM(1.5h) & $134.28 \pm 10.081$ & $81.15 \pm 10.031$ \\
\hline & $4: 00$ PM(2h) & $134.80 \pm 11.061$ & $81.98 \pm 9.881$ \\
\hline & $5: 00$ PM(3h) & $134.87 \pm 9.781$ & $81.26 \pm 9.631$ \\
\hline & $6: 00$ PM(4h) & $134.10 \pm 9.551$ & $81.07 \pm 9.641$ \\
\hline & $8: 00$ PM(6h) & $135.57 \pm 10.911$ & $81.40 \pm 9.511$ \\
\hline
\end{tabular}

It was shown from Table 2 that the difference was statistically significant when compared the systolic pressure and diastolic pressure immediately after scraping, $0.5 \mathrm{~h}, 1 \mathrm{~h}, 1.5 \mathrm{~h}, 2 \mathrm{~h}, 3 \mathrm{~h}$, $4 \mathrm{~h}$ and $6 \mathrm{~h}$ after scraping with that before scraping $(\mathrm{P}<0.01)$, indicating that scraping can significantly and immediately lower blood pressure of patients with essential hypertension.

\section{Influencing factors of anti-hypertensive effect of scraping}

Non-linear regression analysis was adopted in order to find out the influencing factors of anti-hypertensive effect, and the following regression equation was obtained: decreasing amplitude of blood pressure $(\mathrm{y})=11.556+$ sex $^{*} 1.262+$ age ${ }^{*}$ 0.156 - BMI* 0.010 - heart rate* 0.034 - smoking* $2.059+$ drinking* 0.005 - course of disease* $0.2+$ medication* 4.451 grade of hypertension* 0.74 - TCM syndrome* 1.632 .

R-squared $=0.123$ was obtained based on model metaanalysis, and the equation cannot be explained clearly. Therefore, factor analysis was applied to the above influencing factors. It was shown that there were three groups of influencing factors: 
A. The first group was related to sex, smoking and drinking. Since the patients who smoked and drank were mostly males, they were interpreted as unhealthy life-style factors.

B. Based on the grouping according to sex, the difference was significant when compared the two groups before treatment $(\mathrm{P}<0.01)$, therefore, the two groups were not comparable.

C. Based on the grouping according to smoking and drinking, the difference was not significant when compared the two groups before treatment $(\mathrm{P}>0.05)$, therefore, the two groups were comparable. It was found from the comparison of diastolic pressure $0.5 \mathrm{~h}, 1 \mathrm{~h}, 1.5 \mathrm{~h}, 2 \mathrm{~h}$ and $3 \mathrm{~h}$ after scraping between the two groups that the difference was statistically significant $(\mathrm{P}<0.05)$, indicating that the anti-hypertensive effect of scraping in patients without smoking or drinking was superior to that in patients with smoking and drinking (Table 3).

Table 3: Comparison of inter-group diastolic pressure before and after treatment.

\begin{tabular}{|c|c|c|c|c|c|c|}
\hline $\begin{array}{l}\text { Diastolic } \\
\text { Pressure }\end{array}$ & & $\begin{array}{c}\text { Smoking Or } \\
\text { Drinking History }\end{array}$ & Case & Mean Value & $\begin{array}{l}\text { Standard } \\
\text { Deviation }\end{array}$ & $\mathbf{P}$ 值 \\
\hline \multirow{6}{*}{ Before scraping } & 1:45 PM & None & 67 & 84.06 & 11.02 & 0.076 \\
\hline & & Yes & 22 & 89.09 & 10.06 & \\
\hline & $2: 30 \mathrm{PM}(0.5 \mathrm{~h})$ & None & 67 & 79.31 & 10.13 & 0.018 \\
\hline & & Yes & 22 & 86.36 & 10.28 & \\
\hline & 3:00 PM(1h) & None & 67 & 79.7 & 9.39 & 0.016 \\
\hline & & Yes & 22 & 85.91 & 10.35 & \\
\hline \multirow{6}{*}{ After scraping } & $3: 30$ PM(1.5h) & None & 67 & 79.67 & 9.29 & 0.029 \\
\hline & & Yes & 22 & 85.64 & 11.09 & \\
\hline & 4:00 PM(2h) & None & 67 & 80.66 & 9.26 & 0.038 \\
\hline & & Yes & 22 & 86 & 10.83 & \\
\hline & 5:00 PM(3h) & None & 67 & 79.84 & 9.6 & 0.025 \\
\hline & & Yes & 22 & 85.59 & 8.56 & \\
\hline
\end{tabular}

D. The second group was related with age, course of disease and medication which were interpreted as hypertension state factors.

E. Patients younger than 45 years old, patients with 45-60 years old and patients older than 60 years old were divided into three groups, the difference was not significant

Table 4: Comparison of decreasing amplitude of diastolic pressure $6 \mathrm{~h}$ after scraping among the three groups.

\begin{tabular}{|c|c|c|c|c|c|}
\hline Variable & $\begin{array}{c}\text { Age } \\
\text { Category }\end{array}$ & Case & $\begin{array}{c}\text { Mean } \\
\text { Value }\end{array}$ & $\begin{array}{c}\text { Standard } \\
\text { Deviation }\end{array}$ & P Value \\
\hline \multirow{2}{*}{$\begin{array}{c}\text { After } \\
\text { scraping } \\
6 \mathrm{~h}\end{array}$} & $\begin{array}{c}<45 \\
\text { years }\end{array}$ & 14 & 8.07 & 7.44 & \multirow{2}{*}{0.02} \\
\cline { 2 - 5 } & $\begin{array}{c}45 \sim 60 \\
\text { years }\end{array}$ & 33 & 3.52 & 5.68 & \\
\hline & $\begin{array}{c}>0 \\
\text { years }\end{array}$ & 42 & 2.81 & 5.27 & \\
\hline
\end{tabular}

F. The course of disease of hypertension patients was divided into $\leq 5$-year group, 5-10-year group and $>10$-year group. The difference was not significant when compared the blood pressure among the three groups before treatment $(\mathrm{P}>0.05)$, therefore, the three groups were comparable; it was found from the comparison of systolic pressure among the three groups $1.5 \mathrm{~h}$ after scraping that the difference was statistically significant $(\mathrm{P}<0.05)$, indicating that anti- when compared the three groups before treatment $(\mathrm{P}>0.05)$, therefore, the three groups were comparable; it was found from the comparison of decreasing amplitude of diastolic pressure $6 \mathrm{~h}$ after scraping among the three groups that the difference was statistically significant $(\mathrm{P}<0.05)$, indicating that age was inversely proportional to the decreasing amplitude of blood pressure after scraping (Table 4).

hypertensive effect of scraping in patients with the course of disease between 5 to 10 years was superior to that in patients with the course of disease within 5 years and more that 10 years (Table 5).

Table 5: Comparison of inter-group systolic pressure before and after treatment.

\begin{tabular}{|c|c|c|c|c|c|}
\hline $\begin{array}{l}\text { Systolic } \\
\text { Pressure }\end{array}$ & Course & Case & $\begin{array}{l}\text { Mean } \\
\text { Value }\end{array}$ & $\begin{array}{l}\text { Standard } \\
\text { Deviation }\end{array}$ & P Value \\
\hline \multirow{3}{*}{$\begin{array}{l}\text { Before } \\
\text { treatment }\end{array}$} & $<5$ years & 43 & 149.88 & 11.31 & 0.587 \\
\hline & $\begin{array}{l}5 \sim 10 \\
\text { years }\end{array}$ & 19 & 147.05 & 8.79 & \\
\hline & $\begin{array}{l}>10 \\
\text { years }\end{array}$ & 27 & 148.96 & 9.34 & \\
\hline \multirow{3}{*}{$\begin{array}{c}\text { After } \\
\text { treatment } \\
1.5 \mathrm{~h}\end{array}$} & $<5$ years & 43 & 135.91 & 10.1 & 0.045 \\
\hline & $\begin{array}{l}5 \sim 10 \\
\text { years }\end{array}$ & 19 & 129.58 & 10.25 & \\
\hline & $\begin{array}{l}>10 \\
\text { years }\end{array}$ & 27 & 135 & 9.24 & \\
\hline
\end{tabular}


G. Based on taking anti-hypertensive drugs or not, the difference was not significant according to inter-group comparison before treatment $(\mathrm{P}>0.05)$, therefore, the groups were comparable; it was found from the comparison of decreasing amplitude of systolic pressure between the two groups $1.5 \mathrm{~h}$ and $2 \mathrm{~h}$ after scraping that the difference was statistically significant $(\mathrm{P}<0.05)$, indicating that antihypertensive effect of scraping in patients taking antihypertensive drugs was superior to that in patients without taking anti-hypertensive drugs (Table 6).

Table 6: Comparison of inter-group decreasing amplitude of blood pressure before and after treatment.

\begin{tabular}{|c|c|c|c|c|c|}
\hline $\begin{array}{c}\text { Decreasing } \\
\text { Amplitude } \\
\text { Of Blood } \\
\text { Pressure }\end{array}$ & $\begin{array}{c}\text { Anti- } \\
\text { Hypertensive } \\
\text { Drugs }\end{array}$ & Case & $\begin{array}{c}\text { Mean } \\
\text { Value }\end{array}$ & $\begin{array}{c}\text { Standard } \\
\text { Deviation }\end{array}$ & P Value \\
\hline $\begin{array}{c}1.5 \mathrm{~h} \text { after } \\
\text { treatment }\end{array}$ & None & 34 & 11.21 & 8.47 & 0.033 \\
\hline Yes & 55 & 15.58 & 7.83 & \\
\hline 2h after \\
treatment
\end{tabular}

H. The third group was related with TCM syndrome which was interpreted as TCM syndrome factors.

I. It was shown from the comparison of blood pressure among the four group before scraping that the difference was not significant $(\mathrm{P}>0.05)$, and the groups were comparable. It was found from the comparison of systolic pressure among the four groups immediately after scraping, $0.5 \mathrm{~h}$ and $6 \mathrm{~h}$ after scraping that the difference was statistically significant $(\mathrm{P}<0.05)$, indicating that anti-hypertensive effect of scraping in patients with the type of exuberance of liver fire was the best, better in patients with the type of yin deficiency with yang hyperactivity, slightly poor in patients with the type of phlegm-damp congestion and exuberance, and worst in patients with the type of deficiency of both yin and yang (Table 7).

Table 7: Comparison of inter-group systolic pressure before and after treatment

\begin{tabular}{|c|c|c|c|c|c|}
\hline & $\begin{array}{c}\text { Pattern } \\
\text { Differentiation }\end{array}$ & Case & $\begin{array}{c}\text { Mean } \\
\text { Value }\end{array}$ & $\begin{array}{c}\text { Standard } \\
\text { Deviation }\end{array}$ & $\begin{array}{c}\text { P } \\
\text { Value }\end{array}$ \\
\hline $\begin{array}{c}\text { Systolic } \\
\text { pressure } \\
\text { before } \\
\text { scraping }\end{array}$ & $\begin{array}{c}\text { Exuberance of } \\
\text { liver fires }\end{array}$ & 27 & 149.56 & 11.37 & 0.135 \\
\hline & $\begin{array}{c}\text { Yin deficiency } \\
\text { and yang } \\
\text { hyperactivity }\end{array}$ & 27 & 147.33 & 8.36 & \\
\hline & $\begin{array}{c}\text { Phlegm-damp } \\
\text { congestion and } \\
\text { exuberance }\end{array}$ & 20 & 146.85 & 9.07 & \\
\hline & $\begin{array}{c}\text { Yin and yang } \\
\text { deficiency }\end{array}$ & 15 & 153.87 & 11.54 & \\
\hline
\end{tabular}

\begin{tabular}{|c|c|c|c|c|c|}
\hline \multirow{4}{*}{$\begin{array}{c}\text { Systolic } \\
\text { pressure } \\
\text { after } \\
\text { treatment } \\
6 \mathrm{~h}\end{array}$} & $\begin{array}{l}\text { Exuberance of } \\
\text { liver fire }\end{array}$ & 27 & 131.11 & 9.73 & 0.015 \\
\hline & $\begin{array}{l}\text { Yin deficiency } \\
\text { and yang } \\
\text { hyperactivity }\end{array}$ & 27 & 133.85 & 9.07 & \\
\hline & $\begin{array}{l}\text { Phlegm-damp } \\
\text { congestion and } \\
\text { exuberance }\end{array}$ & 20 & 138.3 & 11.1 & \\
\hline & $\begin{array}{l}\text { Yin and yang } \\
\text { deficiency }\end{array}$ & 15 & 143.07 & 11.75 & \\
\hline
\end{tabular}

\section{Discussion}

By stimulating skin through wiping manipulation, scraping can make subcutaneous capillaries expand or rupture, which can cause local tissue congestion or blood stasis, and make the skin present flushing or purple red spot-like or patchy plaques which are the so called "rash of measles" [4]. In the meantime, local blood stasis can induce the body to increase its recovery ability, and accelerate local blood circulation and metabolism, so warm feeling can be presented locally. It has been confirmed from modern medical researches [5-9] that scraping can improve the blood perfusion and temperature in local meridian circulation areas. The efficacy of scraping in traditional Chinese medicine is called opening striae and interstices, activating blood vessels, unblocking meridians and dissipating pathogenic toxin.

Since blood pressure is a variable with continuity and volatility, common people have two peaks and two valleys; in order to avoid the influence of physiological fluctuation of blood pressure on this study, we selected the period from $13: 00-14: 00 \mathrm{pm}$. (valleys) to $18: 00-20: 00 \mathrm{pm}$. (peaks) to conduct treatment and monitor blood pressure. It was shown from the study that the systolic pressure and diastolic pressure immediately after scraping, $0.5 \mathrm{~h}, 1 \mathrm{~h}, 1.5 \mathrm{~h}, 2 \mathrm{~h}, 3 \mathrm{~h}, 4 \mathrm{~h}$ and $6 \mathrm{~h}$ after scraping were lower than that before scraping, indicating that scraping can significantly and immediately lower blood pressure of patients with essential hypertension.

It was found based on factor analysis that there are three groups of factors influencing the anti-hypertensive effect of scraping: the first group is smoking and drinking; the second group is age, course of disease and medication; and the third group was TCM syndrome. It was indicated from stratification analysis on the above factors that:

A. The anti-hypertensive effect of scraping in patients without smoking or drinking was superior to that in patients with smoking and drinking, which was related to the fact that smoking and drinking are the risk factors of hypertension onset; therefore, smoking cessation and temperance should be performed clinically in patients with smoking and drinking.

B. The elder the patients with essential hypertension, the smaller the decreasing amplitude of blood pressure of 
scraping; the anti-hypertensive effect of scraping in patients with the course of disease between 5 to 10 years and with stable state of illness was superior to that in patients with the course of disease within 5 years and more that 10 years, and with unstable state of illness. Most patients with the course of disease within 5 years in this study have not taken anti-hypertensive drugs. The decreasing amplitude of blood pressure of scraping in patients taking anti-hypertensive drugs was greater than that in patients without taking antihypertensive drugs, indicating that scraping can enhance the sensibility of body to anti-hypertensive drugs in patients having taken anti-hypertensive drugs but whose blood pressure has not been controlled within normal range or treat hypertension through other therapeutic targets.

C. The anti-hypertensive effect of scraping in patients with the type of exuberance of liver fire was superior to that in patients with the type of yin deficiency with yang hyperactivity, phlegm-damp congestion and exuberance, and deficiency of both yin and yang, indicating that the efficacy of scraping for heat pattern (excess heat or deficiency heat) was superior to that for cold pattern, which was related with the theory of traditional Chinese medicine that scraping therapy focused on discharging heat and expelling toxin.

D. In conclusion, it was found from the clinical observation of scraping therapy on essential hypertension that scraping can lower the blood pressure of patients with essential hypertension, and has the best efficacy in young and middleaged patients without smoking and drinking, with stable state of illness and are taking anti-hypertensive drugs, and patients with the type of exuberance of liver fire or yin deficiency with yang hyperactivity.

\section{References}

1. (2011) Revision committee of chinese guideline for prevention and treatment of hypertension. chinese guideline for prevention and treatment of hypertension 2010. Chin J Hypertens 19(8): 701-743.

2. Wang YY, Yang JS (2011) Current situation and prospect of standard research on scraping in china. Chin J Inf Tradit Chin Med (Chin) 18(12): 4-6.

3. Zheng XY (2002) Guidelines of clinical research on chinese new herbal medicine (trial). Beijing: China Medical Science Press. Pp. 7377.

4. Wang YY, Yang JS (2010) Comparative study on scraping in ancient and modern times. J Tradit Chin Med (Chin) 51(3): 274-277.

5. Xu QY, Yang JS, Yang L (2011) Observation of the effect of scraping on the body temperature and blood perfusion on the back of healthy people. 2011 annual meeting symposia of China Association of Acupuncture-moxibustion. Beijing: China Association of Acupuncture-moxibustion PP. 19-24.

6. Niesen A,Knoblauch NT, Dobos Gj, Michalsen A, Kaptchuk TJ (2007) The effect of Gua Sha treatment on the microcirculation of surface tissue:a pilot study in healthy subjects. Explore (NY) 3(5): 456-466.

7. Xu QY, Yang JS, Yang L (2013) Effect of scraping at acupoints on blood perfusion of skin microcirculation on the homolateral meridian. Acup Res 38(1): 52-56.

8. Xu Q Y, Yang JS, Yang Li (2011) Effects of different scraping techniques on body surface blood perfusion volume and local skin temperature of healthy subjects. Journal of Traditional Chinese Medicine 31(4): 316-320.

9. Tian YY, Wang YY, Luo MF (2009) Comparative study on the effect of scraping on blood perfusion and histomorphology of skin of rabbits. J Extern Ther Tradit Chin Med (Chin) 18(6): 8-9.

\section{Your next submission with Juniper Publishers will reach you the below assets}

- Quality Editorial service

- Swift Peer Review

- Reprints availability

- E-prints Service

- Manuscript Podcast for convenient understanding

- Global attainment for your research

- Manuscript accessibility in different formats ( Pdf, E-pub, Full Text, Audio)

- Unceasing customer service

Track the below URL for one-step submission https://juniperpublishers.com/online-submission.php 